\title{
Sociodemographic and clinical factors affecting the quality of life of patients with chronic obstructive pulmonary disease
}

This article was published in the following Dove Press journal: International Journal of COPD

\author{
Joanna Rosińczuk' \\ Maria Przyszlak ${ }^{2}$ \\ Izabella Uchmanowicz ${ }^{3}$ \\ 'Department of Nervous System \\ Diseases, Faculty of Health Sciences, \\ Wroclaw Medical University, Wroclaw, \\ Poland; ${ }^{2}$ Center of Postgraduate \\ Education for Nurses and Midwives, \\ Warsaw, Poland; ${ }^{3}$ Division of Nursing \\ in Internal Medicine Procedures, \\ Wroclaw Medical University, \\ Wroclaw, Poland
}

Background: COPD remains a significant challenge for contemporary medicine. It is one of the most common respiratory illnesses and leads to disability as well as deteriorating patient's quality of life (QOL).

Objective: The objective of this study was to determine the impact of selected sociodemographic and clinical factors on QOL and level of illness acceptance (LIA) of patients with COPD.

Design: This study was a cross-sectional, prospective, observational study.

Patients and methods: The study involved 100 patients (34 women and $66 \mathrm{men}$ ) suffering from COPD for at least half a year, treated in the Allergology Clinic at the Department of Internal Medicine, Geriatrics and Allergy, Wroclaw Medical University in Poland. Standardized questionnaires such as Short Form-36 Health Survey, Saint George's Respiratory Questionnaire, Acceptance of Illness Scale, and COPD Author's Questionnaire were used to assess QOL and LIA.

Results: Among the most significant results, there were no statistically significant differences between the patients' sex and their QOL and LIA $(P>0.05)$. It has been observed that with an increase in the age of patients, a statistically significant decrease in LIA is observed, especially after 60 years of age $(P=0.001)$. It was found that the higher level of education of the patients was statistically significant in the higher QOL $(P<0.05)$ and in the greater LIA $(P<0.05)$. Interestingly, there was no statistically significant effect of active smoking and overweight on QOL and LIA $(P>0.05)$.

Conclusion: Sex of COPD patients does not affect their QOL or LIA, nonetheless, the age decreases the level of QOL and LIA. Higher education improves QOL scores; however, factors such as dyspnea, longer duration of illness, comorbidities, oxygen therapy undertaking, and family burden of respiratory disease affect deterioration of QOL.

Keywords: chronic obstructive pulmonary disease, sociodemographic factors, clinical factors, quality of life, QOL, the level of illness acceptance, LIA, chronic illness acceptance, observational study, SF-36, Saint George’s Respiratory Questionnaire

\section{Introduction}

COPD is characterized by persistent airflow limitation, which usually progresses and is associated with an increased chronic inflammatory response. ${ }^{1,2}$ The severity of the disease in individual patients is influenced by exacerbations, hospitalizations, and coexisting diseases. ${ }^{3}$ Poor airflow is connected with the presence of emphysema and inflammation progressing in bronchioles. ${ }^{4}$

COPD is one of the most important issues and challenges for contemporary medicine. According to the Global Obstructive Lung Disease (GOLD), COPD is one of the leading causes of morbidity and the fourth leading cause of mortality worldwide. ${ }^{5,6}$ COPD affects 210 million people around the world, ${ }^{7}$ and the current prognoses indicate
Correspondence: Joanna Rosińczuk Division of Nervous System Diseases, Department of Clinical Nursing, Faculty of Health Sciences, Wroclaw Medical University, 5 Bartla Street, 5I-6I8

Wroclaw, Poland

Tel +48 7| 784 I805

Fax +48713419533

Email joanna.rosinczuk@umed.wroc.pl 
that by 2030 it will be the third leading cause of death in the world. ${ }^{8}$ Epidemiological studies show that in most countries, the prevalence of COPD in adults aged $\geq 40$ years is between $6 \%$ and $10 \%$. Estimates show that by 2020 COPD will become the seventh cause of disability. ${ }^{8,9}$

The life of people with a chronic disease changes dramatically and leads to significant deterioration in its quality. ${ }^{10}$ Comparing the needs with existing reality, especially in chronic diseases, occurs on many levels of quality of life (QOL). ${ }^{11}$ The studies conducted on the QOL are an attempt to assess the influence of disease on all areas of human life. The progress of medicine that has taken place in recent years has not significantly reduced morbidity and mortality resulting from chronic diseases. ${ }^{9}$

The criteria applied to define socioeconomic differences include education, income, and occupation. ${ }^{12,13}$ The influence of sociodemographic factors was rarely assessed in the previous studies regarding QOL in patients with COPD. The influence of socioeconomic factors on QOL has been demonstrated in worldwide studies in patients with bronchial asthma, ${ }^{14}$ cerebral stroke, ${ }^{15}$ prostate cancer, ${ }^{16}$ and chronic renal failure. ${ }^{17}$ Only a few publications assess the impact of socioeconomic factors on QOL in COPD, and they present various reports. Some authors confirm, while others completely deny, their influence on QOL. ${ }^{18,19}$

In our opinion, taking into consideration such a significant issue may contribute to the understanding of some determinants of the burden of the disease and its impact in the life of patients with COPD. Therefore, the objective of this study was to determine the impact of selected sociodemographic and clinical factors on QOL and level of illness acceptance (LIA) of patients with COPD.

\section{Patients and methods Patient characteristics}

The study involved a group of 100 adult patients (34 women and 66 men) aged from 39 to 84 years (mean age: 60.9 years) who were recruited under inpatient conditions. All COPD patients were treated for at least 6 months in the Allergology Clinic at the Department of Internal Medicine, Geriatrics, and Allergology, Wroclaw Medical University, Poland.

Up to five comorbidities were observed among the participants of the study. The prevalence of comorbidities for hypertension was $27 \%$ and that for diabetes was $23 \%$. The participants also suffered from atherosclerosis (12\%); circulatory failure (8\%); asthma (7\%); myocardial infarction $(5 \%)$; rheumatoid arthritis and prostatic hypertrophy $(4 \%)$; heart failure, cholelithiasis, and glaucoma (3\%); chronic coronary heart disease, kidney failure, and cerebral stroke
(2\%); as well as other coexisting diseases (7\%). The clinical characteristics of the studied patients including spirometry, duration of disease, GOLD classification, and other important COPD-related variables are summarized in Table 1.

The largest group was 61-70 years old (38\%) and 51-60 years old $(30 \%)$. Fourteen percent of the respondents aged from 41 to 50 years, while the number of respondents aged from 40 to $>70$ years was the same at $9 \%$. When analyzing the place of residence, it was found that the majority of patients $(46 \%)$ live in the cities with over 50,000 people. Of the inhabitants, $39 \%$ of the respondents live in the cities with up to 50,000 people. The remaining $15 \%$ live in the countryside. In the group of women, $62 \%$ of the respondents were married, while $38 \%$ of the respondents were single, while in the male group $52 \%$ were married and $48 \%$ were single.

\section{Ethical consideration}

The study was approved by the Bioethics Committee of Wroclaw Medical University, Poland (approval no KB-481/2015). All participants gave written informed consent prior to study participation. The study was conducted in accordance with the guidelines of the Declaration of Helsinki and the principles of Good Clinical Practice as well as in respect for the rights and dignity of the other person. The research project was not funded by national grants or other external sources.

\section{Qualification criteria}

The inclusion criteria in the study are as follows: 1) age $\geq 18$ years, 2) diagnosed with COPD based on medical examinations, and 3 ) the written informed consent of each patient to participate in the study. The exclusion criteria were 1) no consent to participate in the study, 2) mental disorders or mental illness, and 3) other conditions that make patients unable to fill in surveys. Each patient underwent 1) full history of clinical examination, 2) chest X-ray (anteroposterior and lateral), 3) pulmonary function tests (spirometry), and 4) laboratory tests with blood gas analysis. Additionally, we used flow-volume loops by spirometry as a different test for asthma or COPD, to show whether airflow is appropriate for a particular lung volume. Moreover, the lack of coexistence of mental illness or disorder as exclusion criterion was obtained based on psychiatric consultation.

\section{Study outcomes}

The study attempted to show the correlation between the level of QOL and LIA with selected sociodemographic factors. For this purpose, 15 research problems were identified, with the same number of hypotheses being analyzed. All these items 
Table I Clinical characteristics of the studied COPD patients

\begin{tabular}{|c|c|c|}
\hline Spirometry & $\mathbf{X} \pm \mathbf{S D}$ & Min-Max \\
\hline$\overline{\mathrm{FEV}}$, (L) & $1.36 \pm 0.7$ & $0.5 I-3.5 I$ \\
\hline $\mathrm{FEV}_{1}(\% \mathrm{~N})$ & $48 \pm 15.9$ & $15-84$ \\
\hline Ratio of FEV, to FVC & $0.62 \pm 0.18$ & $0.42-1.24$ \\
\hline Characteristics & $\mathbf{N}$ & $\%$ \\
\hline \multicolumn{3}{|l|}{ Duration of the disease } \\
\hline $0-5$ years & 49 & 49.0 \\
\hline $5-10$ years & 29 & 29.0 \\
\hline $10-15$ years & 13 & 13.0 \\
\hline$>15$ years & 9 & 9.0 \\
\hline \multicolumn{3}{|l|}{ Disease severity by GOLD } \\
\hline I & 3 & 3.0 \\
\hline II & 37 & 37.0 \\
\hline III & 52 & 52.0 \\
\hline IV & 7 & 7.0 \\
\hline \multicolumn{3}{|l|}{ Smoking cigarettes } \\
\hline Yes & 49 & 49.0 \\
\hline No & 51 & 51.0 \\
\hline \multicolumn{3}{|l|}{ Duration of smoking } \\
\hline $0-5$ years & 11 & 11.0 \\
\hline $5-10$ years & 8 & 8.0 \\
\hline $10-15$ years & 13 & 13.0 \\
\hline$>15$ years & 17 & 17.0 \\
\hline \multicolumn{3}{|c|}{ Frequency of dyspnea exacerbations during last month } \\
\hline None & 4 & 4.0 \\
\hline Once a day & 12 & 12.0 \\
\hline More often than twice a day & 18 & 18.0 \\
\hline Several times a week & 25 & 25.0 \\
\hline Only after physical effort & 41 & 41.0 \\
\hline \multicolumn{3}{|c|}{ Frequency of awakening due to COPD symptoms during last month } \\
\hline None & 16 & 16.0 \\
\hline Once a week & 33 & 33.0 \\
\hline Three nights a week or more often & 52 & 51.0 \\
\hline \multicolumn{3}{|c|}{ Hospitalization due to exacerbation of COPD during the last 12 months } \\
\hline Yes & 61 & 61.0 \\
\hline No & 39 & 39.0 \\
\hline \multicolumn{3}{|l|}{ Ability of taking inhaled medications } \\
\hline Yes & 67 & 67.0 \\
\hline No & 33 & 33.0 \\
\hline \multicolumn{3}{|l|}{ The use of oxygen at home } \\
\hline Yes & 19 & 19.0 \\
\hline No & 81 & 81.0 \\
\hline
\end{tabular}

Abbreviations: GOLD, Global Obstructive Lung Disease; Max, maximum value; Min, minimum value; $N$, number of participants; $X$, mean value.

were specified and described in the "Results" section due to their expanded character.

\section{Measurement tools}

First, a detailed analysis of medical data in terms of the present and past clinical conditions of each COPD patient was performed. The main measurement tools for scientific purposes were questionnaire methods. From all of the studied patients, the recent sociodemographic data on gender, age, marital status, education, and livelihoods were collected. All respondents received questionnaires along with written information about the study, which was voluntary and provided full anonymity. The respondents completed questionnaires with the assistance of the investigator. The following research tools were used:

\section{Short Form-36 health survey (SF-36)}

SF-36 is a well-known tool for overall health-related QOL, consisting of 36 questions that make up eight dimensions relating to mental and physical health. The individual questionnaire questions concern 1) physical functioning, 2) role limitations due to physical problems, 3) bodily pain, 4) general health perception, 5) vitality, 6) social functioning (SF), 7) mental health $(\mathrm{MH})$, and (8) role limitation due to emotional problems. ${ }^{20,21}$ 
Saint George's Respiratory Questionnaire (SGRQ) SGRQ consists of 50 questions designed to assess the health status of patients with chronic respiratory diseases. The first part of the questionnaire deals with the assessment of symptom component. The second part consists of two components: 1) activity and 2) impacts. Scores range from 0 to 100 , with higher scores indicating more limitations..$^{22,23}$

\section{Acceptance of Illness Scale (AIS)}

AIS is used to measure the LIA, which consists of adaptability and level of mental discomfort. The scale consists of eight assertions, and in each of them, the investigator determines its state on a 5-point scale. Decisive consent expresses poor adaptation to the disease ( 0 points), and a definite lack of consent ( 5 points) means acceptance of the disease. Therefore, the overall scoring, a general measure of the degree of acceptance of the disease, is in the range of $8-40$ points. A lower total score indicates a lower level of acceptance and stronger mental discomfort. ${ }^{24,25}$

\section{COPD Author's Questionnaire (CAQ)}

CAQ comprises 36 simple structured questions directed at 1) demographic data collection (age, sex, place of residence, education, marital status, source of income, monthly income, and few questions about smoking habits and attempts to quit smoking), 2) selected social data (place of residence and count of residence), as well as 3) selected clinical data (risk factors, dyspnea, cough expulsion, comorbidities, hospitalization due to exacerbation of COPD, current medications, treatment compliance, protective vaccinations, family support, emotional issues related to COPD as well as time of COPD diagnosis, history of COPD in the family, last spirometry, and its results).

\section{Statistical analysis}

All calculations were made using Statistica version 10 software (StatSoft, Dell Inc., Round Rock, Texas, USA). The normality of variable distribution was verified using the Shapiro-Wilk test. Statistical characteristics of the variables are presented as arithmetic means (X), standard deviations (SD), medians (Me), and extreme values (Min-Max). For intergroup comparisons, the Mann-Whitney $U$ test was used (applying this test does not require a group equality). The strength and direction of the relationship between the pairs of variables were evaluated using Spearman's rank-order correlation coefficients (rho). The significance of the interaction between multiple amounts of the level of QOL and LIA predictors was assessed in a multivariate analysis of the variance performed using sigma constraint parameterization. The strength and direction of interaction were assessed by beta $(\beta)$. Pearson's chi-squared test for independent variables was used to examine the relationship between two nominal variables (categorical). Significant differences were set as statistically significant at the level of $P<0.05$.

\section{Results}

\section{Problem I: is the QOL level dependent on sex?}

Hypothesis: male patients show higher QOL than women

There were 34 female and 66 male in the study group. Statistical analysis did not show that females were significantly different from males in terms of either QOL or LIA $(P<0.05)$ (Table 2).

\section{Problem 2: is there a relationship between $\mathrm{QOL}$ and the age of patients?} Hypothesis: patients with COPD over the age of 60 years have lower QOL than younger patients The study group included nine patients under 40 years of age, 14 aged 41-50 years old, 30 aged 51-60 years old, 38 aged 61-70 years, and 9 patients over 70 years of age. Analysis of Spearman (rho) correlation coefficients showed that, with the age of the studied patients, there was a significant increase in the values of (rho $=0.554 ; P<0.001)$ and mental dimensions (rho $=0.332 ; P=0.001$ ) of SF-36, as well as the subscales "Activity" (rho $=0.407 ; P<0.001)$ and "Impact" ( $r$ ro $=0.397$; $P<0.001$ ), and global SGRQ score (rho $=0.383 ; P<0.001$ ). With patients' higher age, there was also statistically significant lower score in AIS (rho $=-0.222 ; P=0.022$ ).

In the next stage, the hypothesis was verified that the cutoff value, above which significant QOL deterioration and LIA decrease, is 60 years (Table 3 ).

\section{Problem 3: is the QOL level dependent on education?}

Hypothesis: patients with higher education are characterized by higher QOL than patients with primary, secondary, and vocational education

The study group included nine patients with primary education, 33 with vocational education, 27 with secondary education, and 31 with higher education. Analysis of Spearman (rho) correlation coefficients showed that, with the level of education of the studied patients, there was a significant decrease in the values of (rho $=-0.3339 ; P=0.001$ ) and mental dimensions (rho $=-0.225 ; P=0.024$ ) of SF-36, as well as the subscales "Symptoms" (rho $=-0.197 ; P=0.049)$, "Activity" (rho $=-0.197$; $P=0.049$ ), and "Impact" (rho $=-0.284 ; P=0.013$ ), and global SGRQ score (rho $=-0.227 ; P=0.023$ ). The level of education 
Table 2 Comparison of the statistical characteristics of particular dimensions of the general and specific QOL and LIA in the subgroups of women and men

\begin{tabular}{|c|c|c|c|c|c|c|c|c|c|}
\hline \multirow[t]{2}{*}{ Scale } & \multicolumn{4}{|c|}{ Female $(n=34)$} & \multicolumn{4}{|c|}{ Male $(n=66)$} & \multirow[t]{2}{*}{$P$-valu } \\
\hline & $x$ & SD & Me & Range & $x$ & SD & Me & Range & \\
\hline \multicolumn{10}{|l|}{ SF-36 } \\
\hline Physical dimension & 52.12 & 20.76 & 58 & $6-83$ & 52.20 & 23.23 & 57 & $8-95$ & 0.799 \\
\hline Mental dimension & 33.32 & 13.93 & 38 & $1-56$ & 31.56 & 13.11 & 35 & $4-56$ & 0.396 \\
\hline \multicolumn{10}{|l|}{ SGRQ } \\
\hline Symptoms & 55.10 & 18.08 & 58 & $6-89$ & 60.01 & 22.91 & 60 & $6-97$ & 0.407 \\
\hline Activity & 45.57 & 14.95 & 48 & $5-73$ & 49.63 & 18.95 & 49 & $5-81$ & 0.407 \\
\hline Impact & 46.50 & 26.32 & 51 & 0-95 & 45.41 & 28.90 & 50 & $0-99$ & 0.945 \\
\hline Global score & 50.28 & 23.22 & 51 & $|-9|$ & 50.03 & $25.4 I$ & 54 & $2-97$ & 0.968 \\
\hline \multicolumn{10}{|l|}{ AIS } \\
\hline Score & 21.71 & 5.95 & 21 & $10-35$ & 22.83 & 6.63 & 23 & $8-35$ & 0.327 \\
\hline
\end{tabular}

Abbreviations: AIS, Acceptance of Illness Scale; LIA, the level of illness acceptance; Me, median value; $P$, level of significance; QOL, quality of life; SD, standard deviations; SF-36, Short Form-36 Health Survey; SGRQ, St George's Respiratory Questionnaire; X, mean value.

of the participants did not have a statistically significant effect on AIS values (rho $=0.178 ; P=0.077$ ).

In the next stage, the hypothesis was verified that people with higher education had higher QOL and LIA than patients with primary, secondary, and vocational education (Table 4).

\section{Problem 4: is there a relationship between the QOL and the place of residence?}

Hypothesis: patients living in the city are characterized by higher QOL than patients living in the countryside

In the study group, there were 15 patients living in countryside, 39 in cities with up to 50,000 people and 46 in cities with over 50,000 people. Analysis of Spearman (rho) correlation coefficients did not show statistically significant effects on physical (rho $=-0,035 ; P=0.728$ ) and mental dimensions (rho $=-0.091 ; P=0.368$ ) of SF-36, as well as the subscales "Symptoms" (rho $=-0.082 ; P=0.418)$, "Activity" (rho $=-0.082 ; P=0.418$ ), and "Impact" (rho $=-0.336$; $P=0.725$ ), and global SGRQ score (rho $=-0.032 ; P=0.749$ ), as well as AIS values (rho $=-0.100 ; P=0.322$ ).

In the next stage, the hypothesis was verified that people living in cities had higher QOL and LIA than those living in the countryside (Table 5).

\section{Problem 5: is the QOL and LIA levels dependent on the incidence of dyspnea? Hypothesis: higher incidence of dyspnea decreases QOL and LIA in patients with COPD}

In the study group, there were four patients who never had dyspnea, 41 with dyspnea after only high physical activity, 33 with dyspnea after moderate exercise, 19 with dyspnea even after a slight activity, and three patients complaining of dyspnea at rest. Analysis of Spearman (rho) correlation coefficients showed that, with an increase in the incidence of dyspnea, there is a statistically significant increase in physical (rho $=0.582 ; P<0.001)$ and mental dimensions $(R=0.442$;

Table 3 Comparison of the statistical characteristics of particular dimensions of the general and specific QOL and LIA in the subgroups of patients at the age of $\geq 60$ years

\begin{tabular}{|c|c|c|c|c|c|c|c|c|c|}
\hline \multirow[t]{2}{*}{ Scale } & \multicolumn{4}{|c|}{ Age $<60$ years $(n=53)$} & \multicolumn{4}{|c|}{ Age $>60$ years $(n=47)$} & \multirow[t]{2}{*}{$P$-value } \\
\hline & $x$ & SD & Me & Range & $x$ & SD & Me & Range & \\
\hline \multicolumn{10}{|l|}{ SF-36 } \\
\hline Physical dimension & 40.74 & 21.62 & 43 & $6-79$ & 65.06 & 14.93 & 67 & $30-95$ & $<\mathbf{0 . 0 0 1}$ \\
\hline Mental dimension & 27.58 & 13.83 & 25 & $\mathrm{I}-52$ & 37.32 & 10.77 & 38 & $14-56$ & $<0.001$ \\
\hline \multicolumn{10}{|l|}{ SGRQ } \\
\hline Symptoms & 50.40 & 20.69 & 52 & $6-97$ & 67.29 & 18.69 & 68 & $29-96$ & $<0.05$ \\
\hline Activity & 41.68 & 17.11 & 43 & $5-81$ & 55.65 & 15.46 & 56 & 24-79 & $<0.001$ \\
\hline Impact & 34.22 & 27.56 & 34 & $0-95$ & 58.82 & 22.17 & 58 & $2-99$ & $<0.001$ \\
\hline Global score & 39.69 & 24.41 & 40 & $|-9|$ & 61.88 & 18.94 & 61 & $8-97$ & $<0.001$ \\
\hline \multicolumn{10}{|l|}{ AIS } \\
\hline Score & 24.25 & 6.08 & 24 & $10-35$ & 20.43 & 6.21 & 19 & $8-35$ & 0.001 \\
\hline
\end{tabular}

Note: $P$-values in bold indicate a significant difference.

Abbreviations: AIS, Acceptance of Illness Scale; LIA, the level of illness acceptance; Me, median value; $P$, level of significance; QOL, quality of life; SD, standard deviations; SF-36, Short Form-36 Health Survey; SGRQ, St George's Respiratory Questionnaire; X, mean value. 
Table 4 Comparison of the statistical characteristics of particular dimensions of the general and specific QOL and LIA in the subgroups of patients with higher education and other higher

\begin{tabular}{|c|c|c|c|c|c|c|c|c|c|}
\hline \multirow[t]{2}{*}{ Scale } & \multicolumn{4}{|c|}{ Other education $(n=69)$} & \multicolumn{4}{|c|}{ Higher education $(n=3 I)$} & \multirow[t]{2}{*}{$P$-value } \\
\hline & $\mathbf{x}$ & SD & Me & Range & $\mathbf{x}$ & SD & Me & Range & \\
\hline \multicolumn{10}{|l|}{ SF-36 } \\
\hline Physical dimension & 57.10 & 19.34 & 63 & $6-95$ & 41.19 & 24.81 & 46 & $8-86$ & 0.003 \\
\hline Mental dimension & 34.41 & 12.59 & 37 & $1-56$ & 27.16 & 13.83 & 29 & $4-49$ & 0.013 \\
\hline \multicolumn{10}{|l|}{ SGRQ } \\
\hline Symptoms & 60.01 & 20.69 & 60 & $6-97$ & $54.6 \mathrm{I}$ & 22.88 & 52 & $6-95$ & 0.186 \\
\hline Activity & 49.63 & I7.II & 50 & $5-8 \mid$ & 45.17 & 18.92 & 43 & $5-79$ & 0.186 \\
\hline Impact & 50.46 & 23.91 & 52 & 0-99 & 35.38 & 33.39 & 25 & 0-95 & 0.018 \\
\hline Global score & 53.95 & 21.08 & 54 & I-97 & 41.59 & 29.61 & 40 & $3-91$ & 0.061 \\
\hline \multicolumn{10}{|l|}{ AIS } \\
\hline Score & 21.33 & 6.23 & 21 & $8-35$ & 24.94 & 6.15 & 24 & $10-35$ & 0.013 \\
\hline
\end{tabular}

Note: $P$-values in bold indicate a significant difference.

Abbreviations: AIS, Acceptance of Illness Scale; LIA, the level of illness acceptance; Me, median value; $P$, level of significance; QOL, quality of life; SD, standard deviations; SF-36, Short Form-36 Health Survey; SGRQ, St George's Respiratory Questionnaire; X, mean value.

$P<0.001)$ of SF-36, as well as the subscales "Symptoms" (rho $=0.471 ; P<0.001$ ), "Activity" (rho $=0.471 ; P<0.001$ ), and "Impact" (rho $=0.549 ; P<0.001$ ), and global SGRQ score (rho $=0.510 ; P<0.001$ ), as well as a significant decrease in AIS values (rho $=-0.478 ; P<0.001$ ).

\section{Problem 6: is there a relationship between $\mathrm{QOL}$ and duration of the disease?}

Hypothesis: patients with COPD for up to 5 years show a higher QOL than patients over 5 years of disease duration

In the study group, there were 10 patients with COPD diagnosed $<1$ year ago, 39 were diagnosed in the last $1-5$ years, 29 were diagnosed 5-10 years prior to the study, 13 were diagnosed 10-15 years prior to the study, six patients were diagnosed 15-20 years earlier, and three patients with $>20$ years preceding the study. Analysis of Spearman (rho) correlation coefficients showed that, with an increase in disease duration, there is a statistically significant increase in physical dimension (rho $=0.355 ; P<0.001$ ) of SF-36, as well as the subscales "Symptoms" (rho $=0.231 ; P=0.021$ ), "Activity" (rho $=0.231 ; P=0.021$ ), and "Impact" (rho $=0.365$; $P<0.001$ ), and global SGRQ score (rho $=0.306 ; P=0.002)$, as well as in AIS values (rho $=-0.364 ; P<0.001)$. The impact of COPD duration has not significantly affected QOL in SF-36 (rho $=0.196 ; P=0.051$ ).

In the next stage, the hypothesis was verified that the cutoff value above which significant QOL deterioration and LIA decrease is the duration of COPD over 5 years (Table 6).

\section{Problem 7: is the QOL and LIA levels dependent on financial income?}

Hypothesis: patients who are affluent show higher QOL and better LIA

In the study group, there were three patients with average income per family member not exceeding 500 PLN per month (about $€ 120$ ), 25 persons with an average income of 500-1,000 PLN (about $€ 120-240$ ), 34 persons with an average income of 1,000-1,500 PLN (about €240-360),

Table 5 Comparison of the statistical characteristics of particular dimensions of the general and specific QOL and LIA in the subgroups of patients living in the city and in the countryside

\begin{tabular}{|c|c|c|c|c|c|c|c|c|c|}
\hline \multirow[t]{2}{*}{ Scale } & \multicolumn{4}{|c|}{ City $(n=85)$} & \multicolumn{4}{|c|}{ Countryside $(n=15)$} & \multirow[t]{2}{*}{$P$-value } \\
\hline & $x$ & SD & Me & Range & $\mathbf{x}$ & SD & Me & Range & \\
\hline \multicolumn{10}{|l|}{ SF-36 } \\
\hline Physical dimension & 50.98 & 22.62 & 56 & $6-95$ & 58.93 & 19.84 & 63 & $21-92$ & 0.243 \\
\hline Mental dimension & 31.08 & 13.02 & 34 & $\mathrm{I}-56$ & 38.27 & 14.02 & 45 & $\mathrm{II}-54$ & 0.023 \\
\hline \multicolumn{10}{|l|}{ SGRQ } \\
\hline Symptoms & 58.16 & 22.34 & 58 & $6-97$ & 59.33 & 15.86 & 60 & $27-96$ & 0.817 \\
\hline Activity & 48.10 & 18.47 & 48 & $5-81$ & 49.07 & 13.12 & 50 & $22-79$ & 0.817 \\
\hline Impact & 43.82 & 27.24 & 48 & 0-99 & 56.90 & 30.12 & 66 & $0-97$ & 0.061 \\
\hline Global score & 48.43 & 24.27 & 51 & I-97 & 59.68 & 24.89 & 62 & $4-92$ & 0.081 \\
\hline \multicolumn{10}{|l|}{ AIS } \\
\hline Score & 22.44 & 6.62 & 23 & $8-35$ & 22.53 & 5.19 & 23 & $|2-3|$ & 0.919 \\
\hline
\end{tabular}

Note: $P$-value in bold indicates a significant difference.

Abbreviations: AIS, Acceptance of Illness Scale; LIA, the level of illness acceptance; Me, median value; $P$, level of significance; QOL, quality of life; SD, standard deviations; SF-36, Short Form-36 Health Survey; SGRQ, St George's Respiratory Questionnaire; X, mean value. 
Table 6 Comparison of the statistical characteristics of particular dimensions of the general and specific QOL and LIA in the subgroups of patients who have been diagnosed with COPD up to 5 years prior to or later

\begin{tabular}{|c|c|c|c|c|c|c|c|c|c|}
\hline \multirow[t]{2}{*}{ Scale } & \multicolumn{4}{|c|}{ Diagnosis $<5$ years $(n=49)$} & \multicolumn{4}{|c|}{ Diagnosis $>5$ years $(n=5 I)$} & \multirow[t]{2}{*}{$P$-value } \\
\hline & $\mathbf{x}$ & SD & Me & Range & $x$ & SD & Me & Range & \\
\hline \multicolumn{10}{|l|}{ SF-36 } \\
\hline Physical dimension & 42.73 & 23.12 & 46 & $8-83$ & 61.24 & 17.38 & 65 & $6-95$ & $<0.001$ \\
\hline Mental dimension & 28.94 & 13.81 & 27 & $4-56$ & 35.25 & 12.24 & 38 & $1-56$ & 0.026 \\
\hline \multicolumn{10}{|l|}{ SGRQ } \\
\hline Symptoms & 52.51 & 19.58 & 55 & $6-88$ & 63.94 & 21.81 & 62 & 6-97 & 0.005 \\
\hline Activity & 43.43 & 16.19 & 45 & $5-73$ & 52.88 & 18.04 & 51 & $5-81$ & 0.005 \\
\hline Impact & 34.76 & 28.05 & 34 & $0-95$ & 56.37 & 23.55 & 58 & 0-99 & $<0.001$ \\
\hline $\begin{array}{l}\text { Global score } \\
\text { AIS }\end{array}$ & 41.44 & 25.30 & 43 & $2-91$ & 58.45 & 20.89 & 58 & $\mathrm{I}-97$ & 0.001 \\
\hline Score & 24.82 & 6.05 & 25 & $10-35$ & 20.18 & 5.94 & 19 & $8-35$ & $<0.001$ \\
\hline
\end{tabular}

Note: $P$-values in bold indicate a significant difference.

Abbreviations: AIS, Acceptance of Illness Scale; LIA, the level of illness acceptance; Me, median value; $P$, level of significance; QOL, quality of life; SD, standard deviations; SF-36, Short Form-36 Health Survey; SGRQ, St George's Respiratory Questionnaire; X, mean value.

17 people with an average income of 1,500-2,000 PLN (about $€ 360-480$ ), and 21 patients with an average income of over 2,000 PLN a month (about €480).

The analysis of Spearman (rho) correlation coefficients showed that, as the average monthly income per family member increased, there is a statistically significant decrease in physical (rho $=-0.443 ; P<0.001$ ) and mental dimensions (rho $=-0.430 ; P<0.001$ ) of SF-36, as well as the subscales "Symptoms" ( $\mathrm{rho}=-0.220 ; P=0.028)$, "Activity" (rho $=-0.220 ; P=0.028$ ), and "Impact" (rho $=-0.510$; $P<0.001$ ), and global SGRQ scores (rho $=-0,467$; $P<0.001$ ), as well as significant increase in AIS values (rho $=0.308 ; P=0.002$ ).

\section{Problem 8: is there a relationship between QOL and smoking?}

Hypothesis: patients currently smoking cigarettes are characterized by more frequent dyspnea and lower QOL than non-smokers

In the study group, there were 49 active smokers and 51 non-smokers. Statistical analysis did not show that active smokers were significantly different from non-smokers in terms of either QOL or LIA scores (Table 7).

\section{Problem 9: does the body mass index (BMI) affect QOL level?}

Hypothesis: obese or overweight or underweight patients exhibit lower QOL than patients with normal BMI

In the study group, there were 40 patients with normal body weight, 50 patients with overweight, and 10 with obesity. Analysis of Spearman (rho) correlation coefficients did not show a statistically significant increase of BMI in physical (rho $=0.052 ; P=0.607$ ) and mental dimensions ( $r h o=-0.118$; $P=0.241)$ of SF-36, as well as the subscales "Activity" (rho $=-0.002 ; P=0.983$ ) and "Impact" (rho $=-0.029$; $P=0.777$ ), and global SGRQ score ( $r$ ho $=-0.043 ; P=0.672$ ), as well as in AIS value (rho $=0.005 ; P=0.958$ ).

In the next stage, the hypothesis was verified that people with abnormal relative weight (overweight or obesity) had worse QOL and lower LIA than patients with normal body weight (Table 8).

Table 7 Comparison of the statistical characteristics of particular dimensions of the general and specific QOL and LIA in the subgroups of patients who are active smokers and non-smokers

\begin{tabular}{|c|c|c|c|c|c|c|c|c|c|}
\hline \multirow[t]{2}{*}{ Scale } & \multicolumn{4}{|c|}{ Active smokers $(n=49)$} & \multicolumn{4}{|c|}{ Non-smokers $(n=5$ I) } & \multirow[t]{2}{*}{$P$-value } \\
\hline & $x$ & SD & Me & Range & $x$ & SD & Me & Range & \\
\hline \multicolumn{10}{|l|}{ SF-36 } \\
\hline Physical dimension & 52.88 & 24.40 & 58 & $8-95$ & 51.49 & 20.35 & 56 & $6-92$ & 0.510 \\
\hline Mental dimension & 32.24 & 14.00 & 36 & $4-56$ & 32.08 & 12.83 & 35 & $\mathrm{I}-54$ & 0.997 \\
\hline \multicolumn{10}{|l|}{ SGRQ } \\
\hline Symptoms & 61.91 & 22.81 & 58 & $6-97$ & 54.91 & 19.62 & 59 & $6-96$ & 0.170 \\
\hline Activity & 51.20 & 18.86 & 48 & $5-81$ & 45.41 & 16.23 & 49 & $5-79$ & 0.170 \\
\hline Impact & 49.49 & 29.64 & 54 & 0-99 & 42.22 & 25.96 & 39 & $0-97$ & 0.109 \\
\hline Global score & 52.56 & 26.59 & 58 & $3-97$ & 47.77 & 22.48 & 47 & $1-92$ & 0.160 \\
\hline \multicolumn{10}{|l|}{ AIS } \\
\hline Score & 21.24 & 7.09 & 20 & $8-35$ & 23.61 & 5.48 & 24 & $10-35$ & 0.073 \\
\hline
\end{tabular}

Abbreviations: $\mathrm{X}$, mean value; SD, standard deviations; Me, median value; $P$, the level of significance; SF-36, Short Form-36 Health Survey; SGRQ, St George's Respiratory Questionnaire; AIS, Acceptance of Illness Scale; QOL, quality of life; LIA, the level of illness acceptance. 
Table 8 Comparison of the statistical characteristics of particular dimensions of the general and specific QOL and LIA in the subgroups of patients with normal and abnormal BMI

\begin{tabular}{|c|c|c|c|c|c|c|c|c|c|}
\hline \multirow[t]{2}{*}{ Scale } & \multicolumn{4}{|c|}{ Normal BMI $(n=40)$} & \multicolumn{4}{|c|}{ Abnormal BMI $(n=60)$} & \multirow[t]{2}{*}{$P$-value } \\
\hline & $x$ & SD & Me & Range & $\mathbf{x}$ & SD & Me & Range & \\
\hline \multicolumn{10}{|l|}{ SF-36 } \\
\hline Physical dimension & 52.63 & 19.56 & 56 & $6-83$ & 51.87 & 24.14 & 59 & $8-95$ & 0.894 \\
\hline Mental dimension & 34.40 & 13.22 & 39 & $\mathrm{I}-56$ & 30.67 & 13.33 & 33 & $4-56$ & 0.130 \\
\hline \multicolumn{10}{|l|}{ SGRQ } \\
\hline Symptoms & 58.82 & 19.44 & 59 & $6-92$ & 58.01 & 22.81 & 56 & $6-97$ & 0.786 \\
\hline Activity & 48.65 & 16.07 & 49 & $5-77$ & 47.98 & 18.86 & 47 & $5-81$ & 0.786 \\
\hline Impact & 48.05 & 27.11 & 53 & 0-95 & 44.27 & 28.58 & 49 & 0-99 & 0.506 \\
\hline Global score & 52.32 & 23.29 & 57 & $|-9|$ & 48.65 & 25.47 & 51 & $3-97$ & 0.425 \\
\hline \multicolumn{10}{|l|}{ AIS } \\
\hline Score & 22.28 & 5.99 & 22 & $12-35$ & 22.57 & 6.71 & 24 & $8-35$ & 0.622 \\
\hline
\end{tabular}

Abbreviations: AIS, Acceptance of Illness Scale; BMI, body mass index; LIA, the level of illness acceptance; Me, median value; P, level of significance; SD, standard deviations; SF-36, Short Form-36 Health Survey; SGRQ, St George's Respiratory Questionnaire; QOL, quality of life; X, mean value.

Problem 10: does support for the disease and its duration affect QOL patients and LIA in this group?

Hypothesis: patients with a short duration of illness who receive family support show a higher QOL and LIA

In the study group, 78 people declared that they received support from their relatives and 22 patients said they did not receive such support (Table 9).

In the next stage, it was verified that support received from relatives was able to neutralize the adverse effects of a longer period of COPD on patients' QOL and LIA. Analysis of interactions of effects by sigma-constraint parameterization showed that support from relatives did not adversely affect longer (over 5 years) duration of COPD on physical $(\beta=0.067 ; P=0.560)$ and mental dimensions $(\beta=0.028$;
$P=0,814)$ of SF-36, as well as the subscales "Symptoms" ( $\beta=-0.132 ; P=0.298)$, "Activity" $(\beta=-0,132 ; P=0.298)$, and the global SGRQ score $(\beta=0.092 ; P=0.430)$, as well as in AIS value $(\beta=-0.144 ; P=0.240)$.

\section{Problem II: is there a relationship between the occurrence of comorbidities and QOL and LIA?}

Hypothesis: patients with comorbidities have lower QOL and worse disease tolerance than non-comorbid patients

In the study group, 56 people presented comorbidities, and 44 patients were free of comorbidities. Patients with comorbidities have shown significantly higher results for physical and mental dimensions of SF-36, as well as the subscales "Symptoms," "Activity," and "Impact," and

Table 9 Comparison of the statistical characteristics of particular dimensions of the general and specific QOL and LIA in the subgroups of patients claiming a proper or the lack of support from relatives

\begin{tabular}{|c|c|c|c|c|c|c|c|c|c|}
\hline \multirow[t]{2}{*}{ Scale } & \multicolumn{4}{|c|}{ Proper support $(n=78)$} & \multicolumn{4}{|c|}{ Lack of support $(n=22)$} & \multirow[t]{2}{*}{$P$-value } \\
\hline & $x$ & SD & Me & Range & $x$ & SD & Me & Range & \\
\hline \multicolumn{10}{|l|}{ SF-36 } \\
\hline Physical dimension & 47.63 & 22.47 & 49 & $6-86$ & 68.27 & 12.18 & 68 & $38-95$ & $<0.001$ \\
\hline Mental dimension & 29.24 & 12.94 & 30 & $\mathrm{I}-56$ & 42.50 & 9.08 & 44 & $19-56$ & $<0.001$ \\
\hline \multicolumn{10}{|l|}{ SGRQ } \\
\hline Symptoms & 55.90 & 21.16 & 56 & $6-97$ & 66.96 & 20.55 & 65 & $6-96$ & 0.015 \\
\hline Activity & 46.24 & 17.50 & 46 & $5-81$ & 55.38 & 16.99 & 54 & $5-79$ & 0.015 \\
\hline Impact & 39.86 & 26.56 & 44 & $0-91$ & 66.80 & 22.27 & 62 & $22-99$ & $<0.001$ \\
\hline Global score & 44.65 & 23.49 & 46 & $\mathrm{I}-90$ & 69.49 & 17.87 & 69 & $35-97$ & $<0.001$ \\
\hline \multicolumn{10}{|l|}{ AIS } \\
\hline Score & 23.15 & 6.52 & 24 & $10-35$ & 19.95 & 5.38 & 19 & $8-29$ & 0.039 \\
\hline
\end{tabular}

Note: $P$-values in bold indicate a significant difference.

Abbreviations: AIS, Acceptance of Illness Scale; LIA, level of illness acceptance; Me, median value; P, level of significance; QOL, quality of life; SD, standard deviations; SF-36, Short Form-36 Health Survey; SGRQ, St George's Respiratory Questionnaire; X, mean value. 
Table 10 Comparison of the statistical characteristics of particular dimensions of the general and specific QOL and LIA in the subgroups of patients with or without comorbidities

\begin{tabular}{|c|c|c|c|c|c|c|c|c|c|}
\hline \multirow[t]{2}{*}{ Scale } & \multicolumn{4}{|c|}{ Presence of comorbidities $(n=56)$} & \multicolumn{4}{|c|}{ Absence of comorbidities $(n=44)$} & \multirow[t]{2}{*}{$P$-value } \\
\hline & $\mathbf{x}$ & SD & Me & Range & $\mathbf{x}$ & SD & Me & Range & \\
\hline \multicolumn{10}{|l|}{ SF-36 } \\
\hline Physical dimension & 63.54 & 15.09 & 65 & $28-95$ & 37.70 & 21.75 & 39 & $6-72$ & $<0.001$ \\
\hline Mental dimension & 37.93 & 10.14 & 39 & $14-56$ & 24.82 & 13.43 & 22 & $1-52$ & $<0.001$ \\
\hline \multicolumn{10}{|l|}{ SGRQ } \\
\hline Symptoms & 69.06 & 17.24 & 68 & 29-97 & 44.69 & 18.33 & 48 & $6-82$ & $<0.001$ \\
\hline Activity & 57.12 & 14.26 & 56 & $24-81$ & 36.96 & 15.16 & 39 & $5-67$ & $<0.001$ \\
\hline Impact & 58.98 & 20.53 & 58 & $19-99$ & 28.98 & 27.21 & 25 & 0-95 & $<0.001$ \\
\hline Global score & 61.87 & 17.23 & 61 & 29-97 & 35.16 & 24.52 & 38 & $|-9|$ & $<0.001$ \\
\hline \multicolumn{10}{|l|}{ AIS } \\
\hline Score & 20.02 & 5.62 & 19 & $8-35$ & 25.55 & 6.03 & 26 & $10-35$ & $<0.001$ \\
\hline
\end{tabular}

Note: $P$-values in bold indicate a significant difference.

Abbreviations: AIS, Acceptance of Illness Scale; LIA, level of illness acceptance; Me, median value; P, level of significance; QOL, quality of life; SD, standard deviations; SF-36, Short Form-36 Health Survey; SGRQ, St George's Respiratory Questionnaire; X, mean value.

global SGRQ scores that indicate lower QOL, as well as significantly lower AIS values than those who did not suffer from comorbidities that indicate worse acceptance of disease (Table 10).

\section{Problem 12: does a positive family history affect lower QOL and worse LIA?}

Hypothesis: patients from families where one parent suffers from respiratory illnesses are more likely to be hospitalized and have a lower QOL and have a worse LIA

In the study group, 48 patients were with a positive family history of respiratory diseases and 52 patients were with no family history of such diseases. It has been shown that patients with a positive family history of respiratory illness have significantly higher physical dimension of SF-36, as well as the subscales "Symptoms," "Activity," and "Impact," and SGRQ global scores, as well as significantly lower AIS values than patients whose closest relatives did not have respiratory diseases. There were no significant differences in mental dimension of SF-36 (Table 11).

\section{Problem 13: is QOL dependence associated with the use of oxygen therapy?}

Hypothesis: patients using oxygen therapy show higher QOL than patients who do not use it

In the study group, 19 patients were undertaking oxygen therapy and 81 patients did not require oxygen therapy. It has been shown that patients receiving oxygen therapy presented significantly higher physical and mental dimensions of SF-36, as well as the subscales "Symptoms," "Activity," "Impact," and global SGRQ scores, as well as significantly

Table I I Comparison of the statistical characteristics of particular dimensions of the general and specific QOL and LIA in the subgroups of patients with positive and negative family history of respiratory diseases

\begin{tabular}{|c|c|c|c|c|c|c|c|c|c|}
\hline \multirow[t]{2}{*}{ Scale } & \multicolumn{4}{|c|}{ Positive family history $(n=48)$} & \multicolumn{4}{|c|}{ Negative family history $(n=52)$} & \multirow[t]{2}{*}{$P$-value } \\
\hline & $\mathbf{x}$ & SD & Me & Range & $\mathbf{x}$ & SD & Me & Range & \\
\hline \multicolumn{10}{|l|}{ SF-36 } \\
\hline Physical dimension & 57.71 & 21.43 & 63 & $6-95$ & 47.06 & 22.09 & 49 & $8-83$ & 0.019 \\
\hline Mental dimension & 32.98 & 12.89 & 36 & $1-56$ & 31.40 & 13.84 & 36 & $4-56$ & 0.704 \\
\hline \multicolumn{10}{|l|}{ SGRQ } \\
\hline Symptoms & 63.89 & 22.12 & 61 & $6-97$ & 53.22 & 19.61 & 55 & $6-92$ & 0.018 \\
\hline Activity & 52.84 & 18.29 & 50 & $5-81$ & 44.01 & 16.22 & 45 & $5-77$ & 0.018 \\
\hline Impact & 52.46 & 27.10 & 53 & 0-99 & 39.62 & 27.50 & 44 & $0-97$ & 0.028 \\
\hline Global score & 56.14 & 23.81 & 57 & I-97 & 44.56 & 24.16 & 45 & $2-92$ & 0.021 \\
\hline \multicolumn{10}{|l|}{ AIS } \\
\hline Score & 20.94 & 6.29 & 20 & $8-35$ & 23.85 & 6.24 & 24 & $10-35$ & 0.020 \\
\hline
\end{tabular}

Note: $P$-values in bold indicate a significant difference.

Abbreviations: AIS, Acceptance of Illness Scale; LIA, level of illness acceptance; Me, median value; P, level of significance; QOL, quality of life; SD, standard deviations; SF-36, Short Form-36 Health Survey; SGRQ, St George's Respiratory Questionnaire; X, mean value. 
Table 12 Comparison of the statistical characteristics of particular dimensions of the general and specific QOL and LIA in the subgroups of patients undertaking oxygen therapy or not

\begin{tabular}{|c|c|c|c|c|c|c|c|c|c|}
\hline \multirow[t]{2}{*}{ Scale } & \multicolumn{4}{|c|}{ Presence of oxygen therapy $(n=19)$} & \multicolumn{4}{|c|}{ Lack of oxygen therapy $(n=8 I)$} & \multirow[t]{2}{*}{$P$-value } \\
\hline & $\mathbf{x}$ & SD & Me & Range & $\mathbf{x}$ & SD & Me & Range & \\
\hline \multicolumn{10}{|l|}{ SF-36 } \\
\hline Physical dimension & 73.47 & 10.43 & 70 & $57-95$ & 47.17 & 21.42 & 50 & $6-83$ & $<0.001$ \\
\hline Mental dimension & 43.26 & 7.32 & 44 & $28-56$ & 29.56 & 13.13 & 30 & $\mathrm{I}-56$ & $<0.001$ \\
\hline \multicolumn{10}{|l|}{ SGRQ } \\
\hline Symptoms & 78.71 & $13.5 \mid$ & 83 & $5 I-96$ & 53.56 & 20.13 & 55 & $6-97$ & $<0.001$ \\
\hline Activity & 65.10 & 11.17 & 69 & $42-79$ & 44.30 & 16.65 & 46 & $5-81$ & $<0.001$ \\
\hline Impact & 72.68 & 16.54 & 72 & $34-99$ & 39.47 & 26.29 & 43 & $0-97$ & $<0.001$ \\
\hline Global score & 72.01 & 15.15 & 72 & $37-97$ & 44.98 & 23.56 & 46 & $1-92$ & $<0.001$ \\
\hline \multicolumn{10}{|l|}{ AIS } \\
\hline Score & 18.26 & 5.08 & 18 & $8-27$ & 23.43 & 6.31 & 24 & $10-35$ & 0.001 \\
\hline
\end{tabular}

Note: $P$-values in bold indicate a significant difference.

Abbreviations: AIS, Acceptance of Illness Scale; LIA, level of illness acceptance; Me, median value; P, level of significance; QOL, quality of life; SD, standard deviations; SF-36, Short Form-36 Health Survey; SGRQ, St George's Respiratory Questionnaire; X, mean value.

lower AIS values than those who did not require oxygen therapy (Table 12).

\section{Problem 14: does anxiety in COPD women have a greater effect on lowering of QOL than men's anxiety?}

Hypothesis: female patients are more likely to have anxiety than men of the same age

In the study group, 23 patients declared that they had no anxiety disorder, and for 22, 33, and 22 patients, anxiety was a small, medium, and large problem, respectively. Spearman's correlation coefficient (rho) analysis showed that, with increased anxiety, there is a statistically significant increase in physical (rho $=0.640 ; P<0.001$ ) and mental dimensions (rho $=0.601, P<0.001$ ) of SF-36, as well as the subscales "Symptoms" (rho =0.567; $P<0.001$ ), "Activity" (rho =0.567; $P<0.001$ ), and "Impact" (rho $=0.665 ; P<0.001$ ) and the global SGRQ score (rho $=0.687 ; P<0.001$ ), as well as a significant decrease in AIS values (rho $=-0.630 ; P<0.001$ ).

In the next stage of the analysis, whether the sex and age of the patients increased the adverse effects of anxiety on QOL and LIA was verified. Analysis of the effects of the sigma-constraint-based interaction showed that the sex of the respondents and their age did not aggravate the adverse effects of anxiety on physical dimension $(\beta=0.025$; $P=0.796$ for sex and $\beta=-0.084 ; P=0.431$ for age) of SF-36, as well as the subscales "Symptoms" $(\beta=-0.195 ; P=0.098$ and $\beta=-0.144 ; P=0.333)$, "Activity" $(\beta=-0.195 ; P=0.098$ and $\beta=-0.144 ; P=0.333)$, "Impact" $(\beta=-0.040 ; P=0.724$ and $\beta=-0.070 ; P=0.571)$, and the global SGRQ score $(\beta=-0.030$; $P=0.780$ and $\beta=-0.060 ; P=0.607)$, as well as AIS values $(\beta=-0.004 ; P=0.973$ and $\beta=0.104 ; P=0.419)$.

\section{Problem 15: is there a relationship between the duration of COPD and anxiety? \\ Hypothesis: anxiety in women with COPD has \\ a greater effect on decreasing of QOL than men's anxiety}

Analysis of interactions of effects by sigma-constraint parameterization did not show significant interactions between patients' sex and the adverse effects of long-term COPD and the occurrence of anxiety on physical $(\beta=0.017 ; P=0.865)$ and mental dimensions $(\beta=0.027 ; P=0.806)$ of SF-36, as well as the subscales "Activity" $(\beta=-0.004 ; P=0.970)$ and "Impact" ( $\beta=0.092 ; P=0.396)$, and global SGRQ score $(\beta=0.080$; $P=0.450)$, as well as AIS values $(\beta=0.112 ; P=0.305)$.

\section{Discussion}

Today, increasing attention is paid to QOL in chronic diseases of the respiratory system. Health-related QOL studies confirm that people with COPD require holistic approach by health care workers who should take into account not only the medical parameters but also other indicators that influence the overall well-being, that is, mental status or socioeconomic status. Thus, it is necessary to carry out studies detecting potential determinants affecting the assessment of QOL in COPD patients, and identifying these factors will be helpful in planning comprehensive care plan for this group of patients.

The results of our study show that along with age there is a significant reduction of both QOL and LIA in COPD patients. These changes are particularly evident in patients over 60 years. Similar results were obtained by Grochans et a ${ }^{26}$ in studies on the Polish population, which found that elderly 
people had a lower QOL than younger patients. Our results in this aspect also confirm the results obtained in Polish ${ }^{27}$ and Spanish $^{28}$ studies.

Epidemiological worldwide studies on COPD show that the disease mostly affects men. ${ }^{29,30}$ This is also confirmed by the results of Polish studies by Majda and Józefowska ${ }^{31}$ in their own material, $66 \%$ of participants were male. It has to be noted that studies by Grochans et $\mathrm{al}^{32}$ and Kupcewicz and Abramowicz ${ }^{27}$ did not show sex-related effects on QOL in patients with COPD, and our study did not confirm any correlation either. However, some researchers ${ }^{33,34}$ point to lower QOL levels in women with COPD.

COPD is a chronic disease that lowers QOL and causes problems with LIA, and about $20 \%$ of patients are not reconciled to the disease. A similar indicator of disease acceptance is presented by Majda and Józefowska. ${ }^{31}$ In our study, the disease acceptance was 22.8 points for men and 21.7 points for women. Higher LIA scores were obtained by Olek et al, ${ }^{35}$ where disease acceptance score was 24 points in women and 22.5 points in men. Our analysis did not show any significant difference between men and women in terms of either QOL or LIA.

A study by Jankowska-Polańska et $\mathrm{al}^{36}$ showed that LIA was significantly negatively affected by older age, lower education, longer duration of illness, number of hospitalizations, stage of illness, dyspnea, limitations in daily activities, pharmacological treatment, level of knowledge, and applied health behaviors.

Our analysis did not show any significant difference between urban and rural residents in terms of any of the analyzed QOL or LIA domains, except for MH scores obtained in an SF-36 questionnaire which were significantly higher for rural patients. This means that living in rural areas do not adversely affect neither QOL nor LIA in COPD patients. Kupcewicz and Abramowicz ${ }^{27}$ obtained opposite results.

Another factor considered in the study was an exacerbation of dyspnea and its negative effect on QOL and LIA which was found in our study. A similar connection in COPD patients was demonstrated by Jankowska-Polańska et $\mathrm{al}^{36}$ and Kupcewicz and Abramowicz ${ }^{27}$ as well as Kołcz and Rożek-Mróz ${ }^{37}$ in relation to the rehabilitation effect.

Our study confirmed that longer disease duration affects QOL in COPD patients and that it also significantly reduces LIA. Moreover, these unfavorable changes persist even after 5 years after COPD diagnosis. Kupcewicz and Abramowicz ${ }^{27}$ also found that disease duration of $>10$ years had a lower QOL score.
This study logically confirms that decrease in the average monthly income per family member was transferred into a difficult financial situation of COPD patients and is directly reflected in lower QOL and LIA. Many authors point out lower socioeconomic status as a significant factor impeding better QOL levels. ${ }^{38,39}$ A similar relationship was found by Kieczka ${ }^{40}$ and Głębocka and Szarzyńska. ${ }^{41}$

Many studies show that the vast of COPD patients are smokers or ex-smokers. ${ }^{26,42}$ In our study, active smoking did not result in a significant deterioration of QOL or LIA or higher incidence of dyspnea. It should also be mentioned that in our study we observed a surprisingly high group of nonsmoking patients which may indicate an effective secondary prevention and successful education in our COPD patients. Also, Tillmann and Silcock, ${ }^{43}$ in turn, after a comparative analysis of smokers and non-smokers, found no difference in the QOL assessment. Grochans et $\mathrm{al}^{26}$ obtained opposite results and associated smoking with lower QOL in COPD patients. Prigatano et $\mathrm{al}^{44}$ showed that QOL in smokers is lower than that in ex-smokers.

The most important factor in COPD is the nutritional status of the patient. Our findings did not show that individuals with abnormal BMI differed significantly from patients with normal body weight in terms of any of the analyzed QOL or LIA domains. Kupcewicz and Abramowicz ${ }^{27}$ found that nine patients with obesity obtained lower QOL scores than patients with normal body weight.

In the present study, the support of the closest people resulted in the improvement of QOL in patients with COPD and the increase of LIA. However, even this kind of support is not able to neutralize the adverse effect of long-term illness on QOL and LIA for associated conditions. Kurowska and Brojakowska ${ }^{45}$ emphasized the level of social support for COPD patients and observed that QOL in this group of patients differs significantly depending on the support received from the family.

The next stage of the study was the analysis of comorbidities and their impact on QOL and LIA. It should be emphasized that the prevalence of two significant comorbidities in our study was $23 \%$ for diabetes and only $2 \%$ for chronic coronary heart disease, kidney failure, and cerebral stroke, and it may be expected that these patients may be treated as a potentially high-risk group for cardiovascular events in the future perspective and that the preliminary prevention procedures should be implemented immediately. Brodnicka et $\mathrm{al}^{46}$ found comorbidities in $95 \%$ of patients, and Kupcewicz and Abramowicz ${ }^{27}$ reported comorbidities 
in about $40 \%$ ( $56 \%$ in our study). Most common comorbidities were diabetes (46\%), hypertension (46\%), and heart failure $(11 \%)$. The study by Antonelli Incalzi et $\mathrm{al}^{47}$ conducted in a group of 270 patients with COPD enumerated hypertension (28\%), diabetes (14\%), and coronary heart disease (10\%).

Our study also found that a positive family history of respiratory disorders translates into lower QOL (especially in the physical domain) and lower LIA in COPD patients. However, a positive family history is not objectively reflected in the higher frequency of hospital admissions due to exacerbation of COPD.

It was observed that a long-term oxygen therapy in COPD patients is responsible for the significant reduction in QOL. Our study confirms this rule because patients presented significantly lower scores for QOL and AIS than patients who did not receive oxygen therapy. Studies by Andersson et $\mathrm{al}^{48}$ showed that QOL in hospitalized patients who undertook long-term oxygen therapy increased after 3 and 12 months of treatment in their functional and mental status. Eaton et $\mathrm{al}^{49}$ suggest that even a short-term 12-week oxygen therapy is associated with improvement in QOL; however, $41 \%$ of patients refuse to continue home oxygen therapy.

We found that increased anxiety translates into a significant worsening of QOL and lowers LIA in COPD patients. These adverse effects of anxiety are observed regardless of sex and age of the patients. According to a literature review, patients with COPD require psychological support, especially in advanced stages, as they experience a significant change in self-esteem and emotional functioning and SF. The prevalence of anxiety and depression is estimated at $25 \% .^{50}$

Only two studies assess LIA in COPD patients, namely, Jankowska-Polańska et $\mathrm{al}^{36}$ and Olek et al, ${ }^{35}$ that provide confirmation for the present study results. The abovementioned analyses on LIA were influenced by age, education, duration of illness, and severity of dyspnea. These correlations were confirmed in our study. The study results lead to a conclusion that the assessment of QOL in COPD patients allows to define and confirm further determinants affecting the QOL of patients in this group. It helps to deliver an adequate care adapted to the needs of patients with the improvement of QOL as a priority.

\section{Study limitations}

There are few limitations in this study which need to be considered. First, we are aware that comorbidities may be an important confounder for the relationships under study. Therefore, in the future studies, the number as well as the severity of such comorbidities that may interfere with the analyzed relationships concerning or duration of the disease should be taken into consideration. Another potential limitation is the lack of analysis based on the relation to the severity of the disease, limitation of exercise capacity, frequency of exacerbations, and QOL scales. We should also present the severity of COPD or even assign the patients into comparative groups regarding this indicator, which could be a confounding factor for correlations of QOL with age and duration of the disease. An adequate scales such as Medical Research Council for the assessment of COPD-related dyspnea and COPD Assessment Test or evaluation of COPD impact on health status should be also included.

\section{Conclusion}

The present findings showed that Polish patients with COPD had reduced levels of both QOL and LIA. Such determinants as exacerbation of dyspnea, longer duration of illness, comorbidities, use of oxygen therapy, and positive family history of respiratory disease affected QOL negatively. Assessment and identification of selected sociodemographic and clinical factors in COPD patients are likely to improve QOL and LIA and optimize management, leading to better patient outcomes.

\section{Consent for publication}

All coauthors have agreed to the submission and publication of this manuscript. Authors are able to provide a signed consent if required by the Journal Editor.

\section{Data availability}

The authors confirm that all data underlying the findings described in this manuscript is fully available to all interested researchers upon request.

\section{Acknowledgments}

There were no other contributors to the article than the authors. The certificated English language services were provided by an academic highly qualified native English speaker to ensure a proper language quality including syntax, spelling, and grammar issues. This study was conducted under a research project funded by the Ministry of Science and Higher Education in Poland as a part of a statutory grant of the Wroclaw Medical University for maintaining research potential (no ST.E020.17.050).

\section{Author contributions}

All authors of this manuscript meet the authorship criteria according to the latest guidelines of the International 
Committee of Medical Journal Editors (ICMJE), as well as all authors have seen and approved the manuscript being submitted and published. All the authors 1) provided substantial contributions to conception and design, acquisition of data, or analysis and interpretation of data; 2) involved in drafting the article or revising it critically for important intellectual content; 3) had given final approval of the version to be published; and 4) were accountable for all aspects of the work in ensuring that questions related to the accuracy or integrity of any part of the work are appropriately investigated and resolved.

\section{Disclosure}

All authors report no conflicts of interests in this work.

\section{References}

1. Vogelmeier CF, Criner GJ, Martinez FJ, et al. Global Strategy for the Diagnosis, Management, and Prevention of Chronic Obstructive Lung Disease 2017 Report. GOLD Executive Summary. Am J Respir Crit Care Med. 2017;195(5):557-582.

2. Holmes S, Scullion J. A changing landscape: diagnosis and management of COPD. Br J Nurs. 2015;24(8):432, 434, 436-438 passim.

3. Overington JD, Huang YC, Abramson MJ, et al. Implementing clinical guidelines for chronic obstructive pulmonary disease: barriers and solutions. J Thorac Dis. 2014;6(11):1586-1596.

4. Celli BR. Recommendations for the early diagnosis of COPD: the AIMAR view. Multidiscip Respir Med. 2015;10(1):6.

5. Sen E, Guclu SZ, Kibar I, et al. Adherence to GOLD guideline treatment recommendations among pulmonologists in Turkey. Int J Chron Obstruct Pulmon Dis. 2015;10:2657-2663.

6. Bakke PS, Rönmark E, Eagan T, et al. Recommendations for epidemiological studies on COPD. Eur Respir J. 2011;38(6):1261-1277.

7. Rycroft CE, Heyes A, Lanza L, Becker K. Epidemiology of chronic obstructive pulmonary disease: a literature review. Int J Chron Obstruct Pulmon Dis. 2012;7:457-494.

8. Adeloye D, Chua S, Lee C, et al. Global and regional estimates of COPD prevalence: systematic review and meta-analysis. J Glob Health. 2015;5(2):020415.

9. Rosenberg SR, Kalhan R, Mannino DM. Epidemiology of chronic obstructive pulmonary disease: prevalence, morbidity, mortality, and risk factors. Semin Respir Crit Care Med. 2015;36(4):457-469.

10. Benzo RP, Abascal-Bolado B, Dulohery MM. Self-management and quality of life in chronic obstructive pulmonary disease (COPD): the mediating effects of positive affect. Patient Educ Couns. 2016;99(4): 617-623.

11. Jones PW, Watz H, Wouters EF, Cazzola M. COPD: the patient perspective. Int J Chron Obstruct Pulmon Dis. 2016;11(Spec Iss):13-20.

12. Braveman PA, Cubbin C, Egerter $S$, et al. Socioeconomic status in health research: one size does not fit all. JAMA. 2005;294(22):2879-2888.

13. Kargoli F, Shulman E, Aagaard P, et al. Socioeconomic status as a predictor of mortality in patients admitted with atrial fibrillation. Am J Cardiol. 2017;119(9):1378-1381.

14. Sahni S, Talwar A, Khanijo S, Talwar A. Socioeconomic status and its relationship to chronic respiratory disease. Adv Respir Med. 2017;85(2): 97-108.

15. Ullberg T, Glader EL, Zia E, Petersson J, Eriksson M, Norrving B. Associations between ischemic stroke follow-up, socioeconomic status, and adherence to secondary preventive drugs in Southern Sweden: observations from the Swedish Stroke Register (Riksstroke). Neuroepidemiology. 2017;48(1-2):32-38.
16. Larsen SB, Brasso K, Christensen J, et al. Socioeconomic position and mortality among patients with prostate cancer: influence of mediating factors. Acta Oncol. 2017;56(4):563-568.

17. Nicholas SB, Kalantar-Zadeh K, Norris KC. Socioeconomic disparities in chronic kidney disease. Adv Chronic Kidney Dis. 2015;22(1): $6-15$.

18. Archea C, Yen IH, Chen $\mathrm{H}$, et al. Negative life events and quality of life in adults with asthma. Thorax. 2007;62(2):139-146.

19. Ketelaars CA, Schlösser MA, Mostert R, Huyer Abu-Saad H, Halfens RJ, Wouters EF. Determinants of health-related quality of life in patients with chronic obstructive pulmonary disease. Thorax. 1996; 51(1):39-43

20. Pickard AS, Yang Y, Lee TA. Comparison of health-related quality of life measures in chronic obstructive pulmonary disease. Health Qual Life Outcomes. 2011;9:26.

21. Parshall MB, Mapel DW, Rice L, Williams A, O'Reilly J. Predictive validity of short-form health survey [36 items] scales for chronic obstructive pulmonary disease exacerbation. Heart Lung. 2008;37(5): 356-365.

22. Nelsen LM, Kimel M, Murray LT, et al. Qualitative evaluation of the St George's Respiratory Questionnaire in patients with severe asthma. Respir Med. 2017;126:32-38.

23. Morishita-Katsu M, Nishimura K, Taniguchi H, et al. The COPD assessment test and St George's Respiratory Questionnaire: are they equivalent in subjects with COPD? Int J Chron Obstruct Pulmon Dis. 2016;11:1543-1551.

24. Volpato E, Banfi P, Pagnini F. A psychological intervention to promote acceptance and adherence to non-invasive ventilation in people with chronic obstructive pulmonary disease: study protocol of a randomised controlled trial. Trials. 2017;18(1):59.

25. Uchmanowicz I, Jankowska-Polanska B, Chabowski M, Uchmanowicz B, Fal AM. The influence of frailty syndrome on acceptance of illness in elderly patients with chronic obstructive pulmonary disease. Int J Chron Obstruct Pulmon Dis. 2016;11:2401-2407.

26. Grochans E, Bąk A, Reczyńska A, Jurczak A, Szkup-Jabłońska M Brzostek B. Evaluation of quality of life of patients with chronic respiratory diseases. Probl Hyg Epidemiol. 2012;93(3):542-545. Polish [with English abstract].

27. Kupcewicz E, Abramowicz A. Assessment of quality of life in chronic obstructive pulmonary disease patients. Hygeia Public Health. 2014;49(4):805-812. Polish [with English abstract].

28. Carrasco Garrido P, de Miguel Díez J, Rejas Gutiérrez J, et al. Negative impact of chronic obstructive pulmonary disease on the health-related quality of life of patients. Results of the EPIDEPOC study. Health Qual Life Outcomes. 2006;4:31.

29. Mapel DW, Dalal AA, Johnson PT, Becker LK, Hunter AG. Application of the new GOLD COPD staging system to a US primary care cohort, with comparison to physician and patient impressions of severity. Int J Chron Obstruct Pulmon Dis. 2015;10:1477-1486.

30. Karloh M, Fleig Mayer A, Maurici R, Pizzichini MMM, Jones PW, Pizzichini E. The COPD assessment test: what do we know so far? A systematic review and meta-analysis about clinical outcomes prediction and classification of patients into GOLD stages. Chest. 2016;149(2): 413-425.

31. Majda A, Józefowska H. Psychological status patients with chronic obstructive pulmonary disease. Nurs Probl. 2009;4(17):283-293. Polish [with English abstract].

32. Grochans E, Bąk A, Reczyńska A, et al. Socio-demographic contributors to quality of life of patients with asthma and chronic obstructive pulmonary disease. Fam Med Prim Care Rev. 2013;15(4):536-539. Polish [with English abstract].

33. Osman IM, Godden DJ, Friend JA, Legge JS, Douglas JG. Quality of life and hospital re-admission in patients with chronic obstructive pulmonary disease. Thorax. 1997;52(1):67-71.

34. Heijdra YF, Pinto-Plata VM, Kenney LA, Rassulo J, Celli BR. Cough and phlegm are important predictors of health status in smokers without COPD. Chest. 2002;121(5):1427-1433. 
35. Olek D, Uchmanowicz I, Chudiak A, Jankowska-Polańska B. Effect of acceptance of disease on quality of life in patients with chronic obstructive pulmonary disease. Nurs Probl. 2014;22(4):471-476. Polish [with English abstract].

36. Jankowska-Polańska B, Kasprzyk M, Chudiak A, Uchmanowicz I. Effect of disease acceptance on quality of life in patients with chronic obstructive pulmonary disease (COPD). Pneumonol Alergol Pol. 2016; 84(1):3-10.

37. Kołcz A, Rożek-Mróz K. Impact of chronic obstructive pulmonary disease on patients' quality of life. Physiotherapy. 2002;10(2):18-24. Polish [with English abstract].

38. Orbon KH, Schermer TR, van der Gulden JW, et al. Employment status and quality of life in patients with chronic obstructive pulmonary disease. Int Arch Occup Environ Health. 2005;78(6):467-474.

39. Ford ES, Mannino DM, Redd SC, Moriarty DG, Mokdad AH. Determinants of quality of life among people with asthma: findings from the Behavioral Risk Factor Surveillance System. J Asthma. 2004;41(3): 327-336.

40. Kieczka K. Quality of life of patients with asthma and chronic obstructive pulmonary disease living in Mazowieckie and Lublin province. Nurs XXIst Century. 2010;32-33(1-2):17-23. Polish [with English abstract].

41. Głębocka A, Szarzyńska M. Social support and well-being among the elderly. Pol Gerontol. 2005;13(4):255-259. Polish [with English abstract].

42. Tsukino M, Nishimura K, Ikeda A, Koyama H, Mishima M, Izumi T. Physiologic factors that determine the health-related quality of life in patients with COPD. Chest. 1996;110(4):896-903.
43. Tillmann M, Silcock J. A comparison of smokers' and ex-smokers' health-related quality of life. J Public Health Med. 1997;19(3):268-273.

44. Prigatano GP, Wright EC, Levin D. Quality of life and its predictors in patients with mild hypoxemia and chronic obstructive pulmonary disease. Arch Intern Med. 1984;144(8):1613-1619.

45. Kurowska K, Brojakowska M. Support and quality of life in people with chronic obstructive pulmonary disease. Med News. 2010;79(6): 438-444.

46. Brodnicka I, Nowak-Gabryel M, Gabryel M, Grabicki M. Dependence of comorbidities in chronic obstructive pulmonary diseases (COPD) on the age of patients and on the severity of COPD. Med News. 2010;79(5): 362-368. Polish [with English abstract].

47. Antonelli Incalzi R, Fuso L, De Rosa M, et al. Co-morbidity contributes to predict mortality of patients with chronic obstructive pulmonary disease. Eur Respir J. 1997;10(12):2794-2800.

48. Andersson I, Johansson K, Larsson S, Pehrsson K. Long-term oxygen therapy and quality of life in elderly patients hospitalised due to severe exacerbation of COPD. A 1 year follow-up study. Respir Med. 2002;96(11):944-949.

49. Eaton T, Garrett JE, Young P, et al. Ambulatory oxygen improves quality of life of COPD patients: a randomised controlled study. Eur Respir J. 2002;20(2):306-312.

50. Kunik ME, Roundy K, Veazey C, et al. Surprisingly high prevalence of anxiety and depression in chronic breathing disorders. Chest. 2005;127(4):1205-1211.
International Journal of COPD

\section{Publish your work in this journal}

The International Journal of COPD is an international, peer-reviewed journal of therapeutics and pharmacology focusing on concise rapid reporting of clinical studies and reviews in COPD. Special focus is given to the pathophysiological processes underlying the disease, intervention programs, patient focused education, and self management protocols.

\section{Dovepress}

This journal is indexed on PubMed Central, MedLine and CAS. The manuscript management system is completely online and includes a very quick and fair peer-review system, which is all easy to use. Visit http://www.dovepress.com/testimonials.php to read real quotes from published authors. 